\title{
Chromosomal imbalances, 11q21 rearrangement and MECT1-MAML2 fusion transcript in mucoepidermoid carcinomas of the salivary gland
}

\author{
IRMGARD VERDORFER ${ }^{1}$, ANDRE FEHR ${ }^{2}$, JÖRN BULLERDIEK ${ }^{2}$, NINA SCHOLZ ${ }^{1}$, ANDREA BRUNNER ${ }^{1}$, \\ JENS KRUGMANN $^{1}$, MARTINA HAGER ${ }^{3}$, HEIKE HAUFE ${ }^{3}$, GREGOR MIKUZ ${ }^{1}$ and ARNE SCHOLTZ ${ }^{4}$ \\ ${ }^{1}$ Institute of Pathology, Medical University of Innsbruck, Muellerstrasse 44, 6020 Innsbruck, Austria; \\ ${ }^{2}$ Center for Human Genetics, University of Bremen, Leobener Strasse ZHG, 28359 Bremen, Germany; \\ ${ }^{3}$ Institute of Pathology, Medical University of Salzburg, Muellner Hauptstrasse 48, 5020 Salzburg; \\ ${ }^{4}$ Department of Otorhinolaryngology, Medical University of Innsbruck, Anichstrasse 35, 6020 Innsbruck, Austria
}

Received December 30, 2008; Accepted February 26, 2009

DOI: $10.3892 /$ or_00000438

\begin{abstract}
The aim of this study was to determine genetic alterations in mucoepidermoid carcinomas of the salivary gland in association with clinical and histopathological parameters. Nineteen formalin-fixed, paraffin-embedded tumors were analysed by using comparative genomic hybridization (CGH), fluorescence in situ hybridization (FISH) on interphase nuclei and reverse transcriptase-polymerase chain reaction (RT-PCR) for detection of MECT1-MAML2 fusion transcript. The CGH analysis showed an overrepresentation of chromosome $\mathrm{X}$ and losses of entire chromosomes or regions on chromosome 1,2, and 15 as the most frequent copy number changes. In $37 \%$ of the analysed tumors a MAML2-rearrangement by interphase FISH was detected, whereas $58 \%$ of the samples showed expression of MECT1-MAML2 fusion transcript. We conclude that the presence of MAML2rearrangement as well as of MECT1-MAML2 fusion transcript may reflect a more favourable prognosis and may be a useful marker for clinical prediction of the biological behavior of these tumors as previously reported.
\end{abstract}

\section{Introduction}

Mucoepidermoid carcinomas (MECs) are rare malignant neoplasms of variable histopathologic differentiation with unpredictable clinical behavior. These tumors showed a wide age distribution with an incidence peak at about the fifth decade of life. MECs are composed of three different cells

Correspondence to: Dr Irmgard Verdorfer, Institute of Pathology, Medical University of Innsbruck, Muellerstrasse 44, 6020 Innsbruck, Austria

E-mail: irmgard.verdorfer@i-med.ac.at

Key words: mucoepidermoid carcinoma, salivary gland, MECT1MAML2, $\mathrm{t}(11 ; 19)$, comparative genomic hybridization, fluorescence in situ hybridization types: intermediate, epidermoid (squamous) and mucussecreting cells (1). Approximately half of the tumors occur in the parotid glands. Patients with a high grade carcinoma have an unfavorable outcome; however, the clinical and prognostic impacts of molecular aberrations remain unknown, due to the limited number of reported cases in the literature. Genetic analyses on MECs like G-banding, FISH, SKY and CGH revealed genetic losses at chromosome 9p21, 8p, 5p, 16q and $12 \mathrm{p}$ and gains of 7 (2-7).

A specific translocation $\mathrm{t}(11 ; 19)(\mathrm{q} 21 ; \mathrm{p} 13)$ is known, which is associated with two types of salivary gland tumors, namely MECs as well as Warthin's tumors $(8,9)$. The Warthin's tumor, a likewise frequently more occurring benign tumor of the salivary gland with distinctive histomorphological features from that of MEC showed the same translocation $\mathrm{t}(11 ; 19)(\mathrm{q} 21 ; \mathrm{p} 13)$, which is seen also in $60 \%$ of the MECs (10). Further translocations with alternative translocation partner such as $\mathrm{t}(11 ; 17)(\mathrm{q} 22 ; \mathrm{p} 11)$ or $\mathrm{t}(11 ; 13)(24 \mathrm{q} ; \mathrm{q} 12)$ could be found in these tumors (11-16). The target genes in the $\mathrm{t}(11 ; 19)(\mathrm{q} 21 ; \mathrm{p} 13)$ translocation are known (17). Molecular analysis of the translocation $\mathrm{t}(11 ; 19)(\mathrm{q} 21 ; \mathrm{p} 13)$ identified a fusion transcript of the exon 1 of the mucoepidermoid carcinoma translocated-1 gene (MECT1, alias CRTC1, TORC1, $W A M T P 1)$ at $19 \mathrm{p} 13$ with the exons $2-5$ of a novel member of the mastermind-like gene family (MAML2) at 11q21. The fusion transcript activates the transcription of the Notch target genes such as HES1 and HES5 $(18,19)$. This fusion gene is also shared in lung mucoepidermoid carcinoma $(20,21)$. Clear cell hidradenoma of the skin as the third tumor type with an identical MECT1-MAML2 gene fusion was reported by Winnes et al (22) and Behboudi et al (23).

\section{Materials and methods}

Formalin-fixed, paraffin-embedded tumor samples. Nineteen tumor samples from 18 patients, diagnosed from 1988 to 2002 were retrieved from the archives of the Institute of Pathology Innsbruck, Austria and of the Institute of Pathology, Salzburg, Austria. Immunohistochemical examination was done with 
MIB-1 antibody (Dako, Austria, dilution 1:100, autoclave 1 bar, in citrate buffer for $30 \mathrm{~min}$ ) using an automated immunostainer (Nexes, Ventana, Tuscon, AZ, USA). The evaluation of MIB-1 expression was determined as the percentage $<10 \%$ and $>10 \%$ of stained cells.

Comparative genomic hybridization (CGH). To evaluate if tumors have other abnormalities except 11q-aberrations, genomic DNA was extracted from formalin-fixed, paraffinembedded tumor material using standard protocols. Control DNA was prepared similarly from peripheral blood specimens of healthy individuals. Tumor $(1 \mu \mathrm{g})$ and control $(1 \mu \mathrm{g})$ DNAs were labeled with digoxigenin-11-dUTP and biotin-16-dUTP, respectively by nick translation (Roche Diagnostics, Mannheim, Germany). After co-precipitation with $40 \mu \mathrm{g}$ human Cot-1 DNA (Roche Diagnostics) and preannealing to suppress signals from repeated sequences the hybridization was carried out to normal human metaphase cells for 3 days at $37^{\circ} \mathrm{C}$. For detection the slides were stained with avidin-fluorescein isothiocyanate (Vector Labs Burlingame, CA) and anti-digoxigenin-rhodamine (Roche Diagnostics). Chromosomes were counterstained with 4,6diamidino-2-phenylindole and specimens were mounted in antifade solution (Vectashield, Vector Laboratories). Image acquisition was carried out using a fluorescence microscope (Zeiss Axioplan) equipped with a CCD camera (JAI M300) and ISIS software (Metasystems, Altlussheim, Germany). Gains or losses were calculated as significant by the evaluation software when fluorescence ratio values were $<0.8$ and $>1.25$. Pericentromeric, heterochromatic, telomeric regions and chromosome $\mathrm{Y}$ were excluded from the evaluation.

Identification of $t(11 ; 19)$ by fluorescence in situ hybridization (FISH) and reverse transcriptase-polymerase chain reaction (RT-PCR) for detection of MECT1-MAML2 fusion transcript. FISH analysis. Sections $(2 \mu \mathrm{m})$ were made from paraffinembedded tissue blocks. The slide and probe preparations were performed according to the protocol for paraffin specimens of the manufacturer (Vysis Downers Grove, IL, USA) with minor modifications. Briefly, the slides were deparaffinized with three 10-min xylene washes, dehydrated in two 5-min washes in $100 \%$ ethanol. Subsequently, the slides were incubated in $10 \mathrm{mM}$ citric acid buffer for $60 \mathrm{~min}$ at $80^{\circ} \mathrm{C}$, followed by an incubation in a pepsin solution $(0.5 \mathrm{mg} / \mathrm{ml})$, fixed in $4 \%$ formaldehyde for $10 \mathrm{~min}$ and dehydrated in a ethanol series $(70,90,100 \%)$. To evaluate the $\mathrm{CGH}$ results, probes for centromere $2,7,16,17, \mathrm{X}, \mathrm{Y}$, LSI probes for $8 \mathrm{q} 24,9 \mathrm{p} 21,13 \mathrm{q} 14,20 \mathrm{q} 13$ and 22q11.2 as well as telomeric probes for $19 \mathrm{p}$ and $19 \mathrm{q}$ (Vysis) were applied onto the slides in the area of interest. Also a dual break apart probe (ZytoLight MEC I, ZytoVysion, Germany), a mixture of two clone contigs hybridizing to the chromosomal band 11q21 was used. The green-labeled probe (size $\sim 550 \mathrm{~kb}$ ) hybridizes proximal the MAML2 gene, the orange-labeled probe (size $\sim 400 \mathrm{~kb}$ ) distal to $M A M L 2$.

The slides were covered with a glass cover slip, sealed with rubber cement, placed in the HYBrite system (Vysis) and denatured at $80^{\circ} \mathrm{C}$ for $5 \mathrm{~min}$ and hybridized overnight at $37^{\circ} \mathrm{C}$. After two wash steps the slides were counterstained with DAPI in antifade solution. At least 165 nuclei (range 165-321, mean 216) were scored in each case with a fluorescence microscope, equipped with specific filters for SpectrumOrange, SpectrumGreen and DAPI. The images were acquired with a CCD camera and ISIS software.

$R T-P C R$ analysis. Total RNA was extracted from 5-10 formalin-fixed, paraffin-embedded tissue sections $(5 \mu \mathrm{m})$ from 19 MECs using High Pure RNA Paraffin Kit (Roche Diagnostics). Primers for RT-PCR for amplify the MECT1MAML2 fragment with an expected size of $105 \mathrm{bp}$ were METC1 5'-GCCTTCGAGGAGGTCATGA-3' and MAML2 5'-CTTGCTGTTGGCAGGAGA-3'. RT-PCR was run using a denaturation step at $94^{\circ} \mathrm{C}$ for $3 \mathrm{~min}$, followed by 35 cycles of $94^{\circ} \mathrm{C}$ for $45 \mathrm{sec}, 55^{\circ} \mathrm{C}$ for $30 \mathrm{sec}$ and $72^{\circ} \mathrm{C}$ for $30 \mathrm{sec}$. A final extension step was done at $72^{\circ} \mathrm{C}$ for $10 \mathrm{~min}$. To check the quality of the cDNA it was also amplified in a GAPDH fragment with an expected size of $184 \mathrm{bp}$ with the primers forward 5'-TCCATGACAACTTTGGTATC-3' and reverse 5'-TTCAGCTCAGGGATGACCTT-3'.

\section{Results}

Clinical and pathological summary. Seventeen samples were primary tumors and two were lymph node metastases. One of these lymph node metastases occurred in a patient with submandibular MEC within the first year after the initial surgical treatment (cases 9a and 9b, Table I). Distant metastases were not documented. Thirteen of the MECs originated from the major salivary glands with the majority located in the parotid gland and 3 cases derived from the submandibular gland. The remaining 2 tumors occurred in a minor salivary gland (soft palate). Tissue samples were stained with haematoxylin and eosin and classified by a pathologist according to the WHO classification (24). The age range at the time of diagnosis was 27-85 years with a median age of 59.4 years. Twelve of the 18 patients $(66.7 \%)$ were $>50$ years of age. The male to female ratio was $1: 1.6$.

All patients presented one or more signs of symptoms. Clinical presentations were relatively uniform. The first symptom in all cases was non-inflammatory, painless solid tumefaction in the area of a salivary gland. Three parotid tumefactions were associated with facial palsy. Two patients experienced discomfort in the parotid region. Six patients (37.5\%) had clinically positive cervical lymph nodes at the time of their examination; in all cases cervical metastases were confirmed by neck dissection. No patient had any signs of distant metastases at the time of diagnosis.

The tumors were clinically staged according to the TNM system (24). The sizes of the tumors ranged from 1.5 to $7 \mathrm{~cm}$. Duration of symptoms ranged from 4 weeks to 18 months and did not correlate with tumor site or size. All patients were primarily treated with surgery. For tumors of the parotid gland a superficial ( 4 cases) or total (9 cases) parotidectomy was performed, supplemented by a suprahomohyoid (12 cases) or radical neck dissection (in 1 case). The 3 MECs of the submandibular gland were treated with suprahomohyoid neck dissection. Surgical management of MECs of minor salivary gland (2 cases) involved the local excision with suprahomohyoid neck dissection. All surgeries 
Table I. Summary of clinical, histopathological and immunohistochemical data of 19 tumor samples from 18 patients with MEC.

\begin{tabular}{|c|c|c|c|c|c|c|c|c|}
\hline \multirow[t]{2}{*}{ Pat. no. } & \multirow{2}{*}{$\begin{array}{l}\text { Gender/ } \\
\text { Age }\end{array}$} & \multirow[t]{2}{*}{ Tumor } & \multirow[t]{2}{*}{$\mathrm{S}$} & \multirow[t]{2}{*}{$\mathrm{G}$} & \multirow[t]{2}{*}{ TNM } & \multirow{2}{*}{$\begin{array}{l}\text { Tumor localization/ } \\
\text { tumor size }(\mathrm{cm})\end{array}$} & \multicolumn{2}{|c|}{ MIB-1 Expression } \\
\hline & & & & & & & $<10 \%$ & $>10 \%$ \\
\hline 1 & $\mathrm{M} / 31$ & PT & 6 & 2 & $\mathrm{pT} 2 \mathrm{~N} 0$ & Gl. p.r./2.5 & + & \\
\hline 2 & $\mathrm{~F} / 84$ & PT & 3 & 3 & pT3V1N1 & Gl. p.r./4.8 & & + \\
\hline 3 & $\mathrm{M} / 42$ & PT & 3 & 2 & pT1N0 & Gl. p.r./1.8 & + & \\
\hline 4 & $\mathrm{M} / 44$ & PT & 3 & 2 & pT2N0 & Gl. p.r./3 & + & \\
\hline 5 & $\mathrm{M} / 73$ & PT & 5 & 2 & $\mathrm{pT} 1 \mathrm{~N} 2 \mathrm{~b}$ & Gl.p.1./2 & & + \\
\hline 6 & $\mathrm{M} / 47$ & PT & 5 & 1 & T1N0 & Minor salivary gland /1.5 & + & \\
\hline 7 & $\mathrm{~F} / 65$ & LNM & 5 & 3 & N2bM0 & Gl. p. $/ 7^{\mathrm{a}}$ & & + \\
\hline 8 & $\mathrm{~F} / 60$ & PT & 5 & 1 & T1N0 & G1.p.1./1.5 & + & \\
\hline $9 a$ & $\mathrm{M} / 68$ & PT & 3 & 3 & $\mathrm{~T} 2 \mathrm{~N} 2 \mathrm{~b}$ & Gl. subm.r./3.5 & & + \\
\hline $9 b$ & & LNM & & & & Gl. subm. & & + \\
\hline 10 & $\mathrm{~F} / 54$ & PT & 5 & 3 & $\mathrm{pT} 3 \mathrm{~N} 2 \mathrm{~b}$ & G1.p.1./5.5 & & + \\
\hline 11 & $\mathrm{~F} / 82$ & PT & 10 & 3 & T4N1 & Gl.p./6.5 & & + \\
\hline 12 & $\mathrm{~F} / 69$ & PT & 10 & 1 & T2N0M0 & Gl.p.1./3 & + & \\
\hline 13 & $\mathrm{~F} / 64$ & PT & 10 & 3 & pT2N0MX & Gl. subm./2.5 & & + \\
\hline 14 & $\mathrm{~F} / 32$ & PT & 10 & 1 & T1N0 & Gl. p.1./2 & NA & \\
\hline 15 & $\mathrm{~F} / 85$ & PT & 5 & 3 & pT3bN0MX & Gl.p./4.5 & & + \\
\hline 16 & $\mathrm{~F} / 27$ & PT & 5 & 3 & pT2N0MXR1 & Gl. p.r./3.2 & + & \\
\hline 17 & $\mathrm{M} / 82$ & PT & 5 & 2 & pT2N1 & Minor salivary gland/2.5 & + & \\
\hline 18 & $\mathrm{~F} / 61$ & PT & 10 & 2 & T2NOMO & Gl. subm./2.5 & + & \\
\hline
\end{tabular}

Pat. no, patient number; M, male; F, female; PT, primary tumor; LNM, lymph node metastases; S, overall disease survival (years); G, tumor grading (G1, low grade, G2 intermediate, G3 high grade); G1. p.r and Gl. p.1., Glandula parotis right and Glandula parotis left; Gl. subm.,

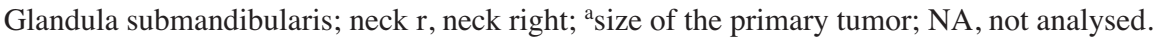

were performed as curative resections, with all cases considered histopathologically to have tumor-free margins. The surgical margins were defined as negative in cases showing a rim of normal tissue of $>3 \mathrm{~mm}$ around the tumor. Surgical treatment was supplemented with radiotherapy in 7 cases. The interval between surgery and the start of radiation therapy was $12-28$ days. The radiotherapy was delivered using Co-60. Doses ranged from 54 to $70 \mathrm{~Gy}$ and the duration of therapy ranged from 35 to 42 days.

Follow-up ranged from 4 to 12 years. Of the 18 patients with MECs, 14 (77.8\%) were alive without disease, 2 patients died from other causes (11\%) and 2 patients died from their disease $(11 \%)$. Four patients were free of the disease for 3 years; 8 patients for 5 years, 1 patient for more than 5 years. Five patients lived for $>10$ years and one of them died from another cause. Three patients developed local recurrence 23, 44 and 67 months postoperatively. Each recurrence (case no. $1,8,11)$ appeared in tumors of the parotid gland. The 5year overall disease specific survival rate of all patients was $78 \%$. Fifty percent of our tumors (9 cases) showed MIB-1 expression $>10 \%$. A summary of clinical and histopathological data is given in Table I.

CGH data. Fifteen primary MECs and 2 lymph node metastasis with sufficient DNA were analyzed with CGH.
Copy number alterations were found in 13 of the analyzed 17 MECs $(76.5 \%)$. In total, we detected 35 losses vs. 27 gains (1:1.29) with an average of 1.59 gains and 2.06 losses per tumor. Three of the 17 cases $(17.6 \%)$ showed one aberration, $5.9 \%$ of the cases one $(1 / 17)$ and $52.9 \%$ of the case $(9 / 17)$ three or more aberrations. As the most frequent deviations gain on X (29.4\%), partial or complete losses on chromosome 1, 2 and $15(23.5 \%)$ were detected, followed by gain of $7 / 7 p$, losses of $17 p q, 19 / 19 p$ and $20 / 20 p / 20 q$ in $17.6 \%$ (Table II; Fig. 1).

FISH data. FISH analysis was performed in all 19 tumors. In 7 of 19 tumors $(36.8 \%)$ a MAML2-rearrangement at $11 \mathrm{q} 21$ was detected (Table I). As the most frequent, a signal pattern of one orange/green (yellow) signal (representing a normal 11q21 locus and a separate orange and green signal, demonstrating a disrupted $11 \mathrm{q} 21$ region) was seen (Fig. 3). This signal pattern suggests a $t(11 ; 19)$ or a variant of it, involving the $11 \mathrm{q} 21$ region. The other frequent chromosomal aberrations detected by $\mathrm{CGH}$ were confirmed by FISH.

$R T-P C R$ results. The following RT-PCR-analysis showed the presence of a MECT1-MAML2 fusion transcript in 11 cases (57.9\%), including the 7 FISH-positive cases (Fig. 2, not all data shown). A summary of our results is given in Table II. 
Table II. Summary of CGH, FISH and RT-PCR results.

\begin{tabular}{|c|c|c|c|c|}
\hline \multirow[b]{2}{*}{ Pat. no. } & \multicolumn{2}{|l|}{$\mathrm{CGH}$} & \multirow{2}{*}{$\begin{array}{c}\text { FISH with 11q21 } \\
\text { break apart probe } \\
\text { MAML2- } \\
\text { Rearrangement } \\
(\% \text { aberrant cells) }\end{array}$} & \multirow{2}{*}{$\begin{array}{c}\text { RT-PCR } \\
\text { Presence of } \\
\text { MECT1-MAML2 } \\
\text { fusion transcript }\end{array}$} \\
\hline & Losses & Gains & & \\
\hline 1 & $\begin{array}{l}\text { 1pter-p32, 6pter-p21, } \\
\text { 15q22-qter, 17, 20q, } 22\end{array}$ & $18 \mathrm{p}, \mathrm{X}$ & Yes (46) & Yes \\
\hline 2 & $15 \mathrm{q} 22$-qter & 14 & No & Yes \\
\hline 3 & No imbalances & $\mathrm{X}$ & Yes (23) & Yes \\
\hline 4 & No imbalances & $\mathrm{X}$ & Yes (57) & Yes \\
\hline 5 & 8pter-p21.1, 15 & $\mathrm{X}$ & No & No \\
\hline 6 & No imbalances & No imbalances & No & No \\
\hline 7 & $9 \mathrm{q}, 16,17$ pter-q22, 18q & $\begin{array}{l}2 \mathrm{q} 32.1-\mathrm{q} 34,4 \mathrm{q} 26-\mathrm{qter} \\
5 \mathrm{q} 14-\mathrm{q} 23.3,8 \mathrm{q}\end{array}$ & No & No \\
\hline 8 & No imbalances & No imbalances & Yes (50) & Yes \\
\hline $9 \mathrm{a}$ & No imbalances & $19 \mathrm{p}$ & No & No \\
\hline $9 b$ & $\begin{array}{l}5 \mathrm{q} 11-\mathrm{q} 23,14 \mathrm{q} 11-\mathrm{q} 23 \\
17 \text { pter-q23, } \\
\text { 18q,19q }\end{array}$ & $\mathrm{X}^{\mathrm{a}}, 3 \mathrm{q} 26-\mathrm{qter}, 6 \mathrm{q} 22$ & No & No \\
\hline 10 & No imbalances & No imbalances & No & No \\
\hline 11 & $\begin{array}{l}\text { 1pter-p32. } 2^{\mathrm{a}}, 6 \text { pter-p21, 10q23-qter, } \\
\text { 14q22-qter, 15q22-qter, } 22\end{array}$ & $4,7,9 p, 13 q 14-q 31,18$ & No & Yes \\
\hline 12 & No imbalances & No imbalances & Yes (84) & Yes \\
\hline 13 & $3 p, 8 p$ & $5 p, 7 p, 20 p$ & No & Yes \\
\hline 14 & $1^{\mathrm{a}}, 2 \mathrm{q}^{\mathrm{a}}$ & $20 q$ & No & No \\
\hline 15 & $2 \mathrm{q}, 3 \mathrm{p} 21.1-\mathrm{p} 12,4^{\mathrm{a}}, 13$ & 19 & No & Yes \\
\hline 16 & $1 \mathrm{p} 31.1-\mathrm{p} 22.1,2^{\mathrm{a}}$ & $7,19,20$ & Yes (66) & Yes \\
\hline 17 & NA & NA & No & No \\
\hline 18 & NA & NA & Yes (56) & Yes \\
\hline
\end{tabular}

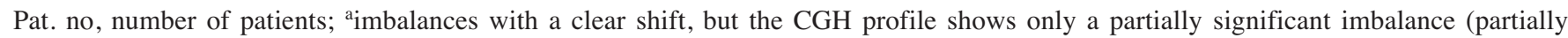
reaching the threshold); NA, not analysed.

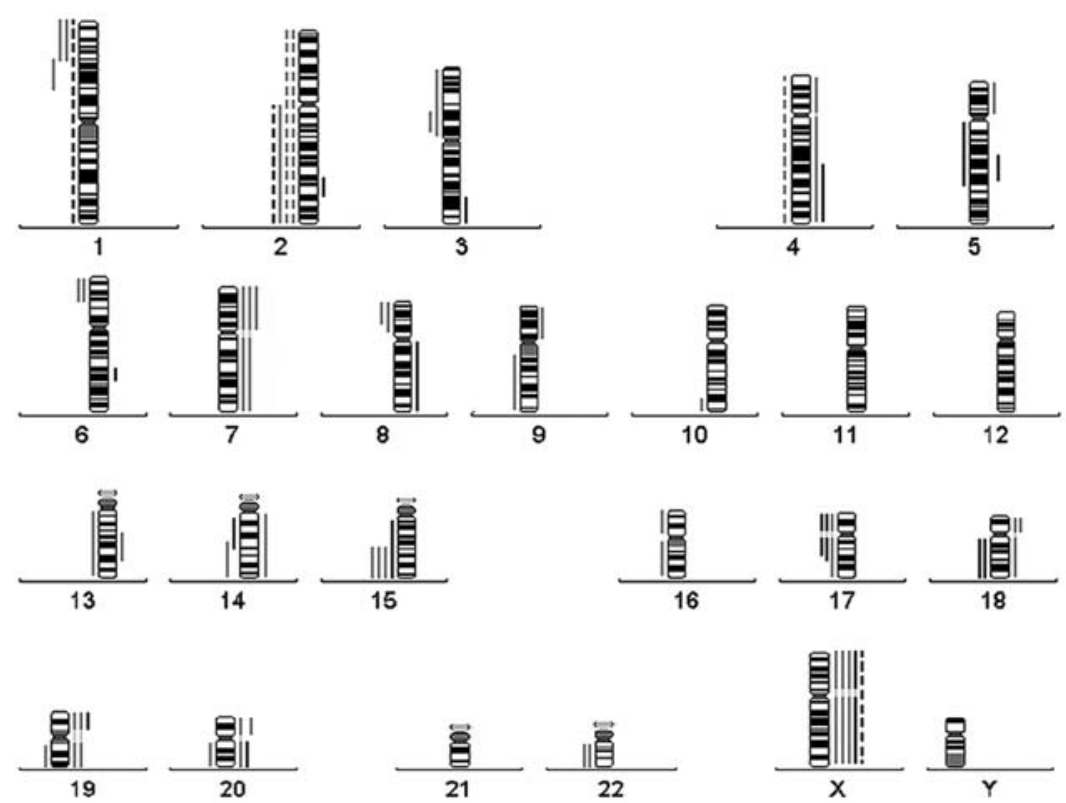

Figure 1. CGH results as summary profile for 17 analyzed MECs. Lines to the left side of the ideograms represent losses, lines to the right side chromosomal gains. Dotted lines indicate imbalances not reaching the diagnostic thresholds; gray lines indicate aberrations deriving from MECT1-MALM2 fusion transcript-positive cases and black lines aberrations from fusion transcript-negative cases. 


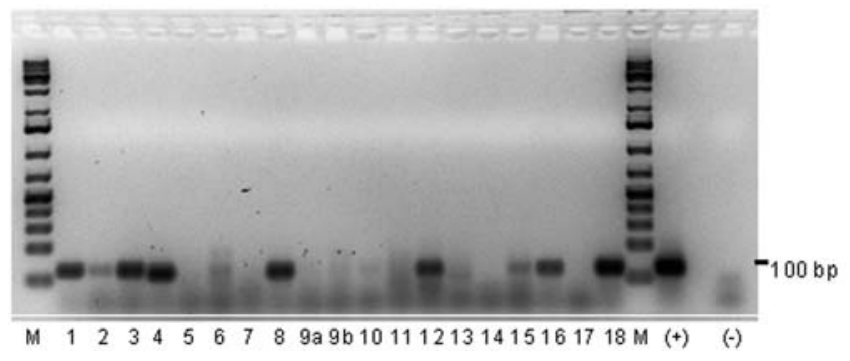

Figure 2. RT-PCR product of MECT1-MAML2 transcript in 19 formalinfixed, paraffin-embedded tumors of 18 patients (not all data shown). M, marker; (+), positive control; (-), negative control.
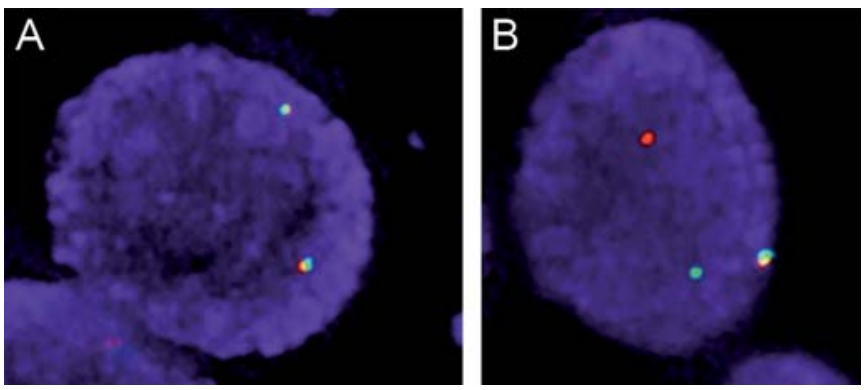

Figure 3. Interphase fluorescence in situ hybridization with the dual color, break apart probe MEC I represents MAML2 rearrangement. (A) Nucleus with two orange/green (yellow) signals indicating two normal 11q21 loci (case 2, Table I). (B) Nucleus with one orange/green (yellow) signal and a separate orange and green signal, caused by a break in 11q21 (case 8, Table I). This signal pattern was the most frequent finding in all analyzed cases.
The two small tumor groups with and without 11q-abnormalities did not allow a statistical analysis. Table III shows the association between the clinicopathologic parameters of patients with and without the presence of the 11q21 aberration.

\section{Discussion}

The presence of aberrations like translocation $\mathrm{t}(11 ; 19)(\mathrm{q} 21 ; \mathrm{p} 13)$ is of special importance for future investigations, providing prognostic and therapeutic relevance. The impact of the METC1-MAML2 fusion on the clinical outcome in MECs is unclear und controversial in the literature. Our data give rise to several commentaries in comparison to the data by other authors:

i) In the present MECs $36.8 \%$ of the tumor samples showed 11q21 rearrangement. The RT-PCR analyzed tumors showed a MECT1-MAML2 fusion product in $57.9 \%$ of the tumors. This frequency is in agreement with studies on MECs by other authors $(11,19)$. Several authors concluded that fusion positive tumors are biologically less aggressive with better clinicopathological behavior in comparison with fusion transcript negative tumors $(11,20,32,33)$.

Behboudi et al (11) demonstrated that patients with fusion gene-positive tumors were substantially younger at clinical presentation, showing a predominance of smaller, high-differentiated low-grade tumors. Fusion-positive patients had a significant lower risk of local recurrence, metastases and tumor-related death. According to the study by Serra et al (20) all analyzed pulmonary MECs with 11q21 rearrangement were low-grade tumors. In contrast to these

Table III. 11q21-rearrangement and expression of MECT1-MAML2 fusion transcript in comparison with clinicohistopathological and genetic data.

MECT1-MAML2-fusion transcript

Mean age (years) $(\mathrm{n}=18)$

Mean tumor size $(n=18)$

MIB-1 expression $(\mathrm{n}=18)$

$$
<10 \%
$$

$>10 \%$

Lymph node metastasis $(\mathrm{n}=18)$

Present

Absent

Tumor grade $(\mathrm{n}=18)$

$$
\text { G I, GII }
$$

G III

Mean survival time (years) $(\mathrm{n}=18)$

No. aberrant CGH-cases

Average gains/aberrant case

Average losses/aberrant case

Aberrant cases with $>2 \mathrm{CNV}$
6

5

$$
\begin{gathered}
6.36(\mathrm{n}=11) \\
(\mathrm{n}=8 / 10,80 \%) \\
2.0 \\
3.25 \\
5(62.5 \%)
\end{gathered}
$$
positive $(n=11)$

$$
59(n=11)
$$

$3.3 \mathrm{~cm}(\mathrm{n}=11)$

$7(64 \%)$

$4(36 \%)$

$2(18 \%)$

$9(82 \%)$

MECT1-MAML2-fusion transcript negative $(n=7)$ $3.4(n=7)$

$2(29 \%)$

$5(71 \%)$

$5(71 \%)$

$2(29 \%)$
4

3

$5.43(\mathrm{n}=7)$

$(\mathrm{n}=5 / 7,714 \%)$

2.2

1.8

$4(80 \%)$ 
authors in the cohort of Tirado and co-workers (33) the fusion transcript METC1-MAML2 showed no association with tumor grade. The lacking of the fusion transcript was significantly associated with metastasis, suggesting that fusion-negative tumors represent a group of biologically aggressive tumors.

However, our study size is too small for a meaningful statistical consideration, but our fusion-negative tumors are predominately associated with occurrence of regional metastases $(71 \%$ vs. $18 \%)$. In comparison to the study of Behboudi et al (11) the estimated median survival for fusion-positive patients was greater than in fusion-negative patients (10 years vs. 1.6 years). The mean survival time in patients with fusion-gene positive tumors in our collective was higher than in patients with fusions-negative tumors (6.36 years vs. 5.43 years). Regarding patient age, tumor grading and tumor size no difference could be observed between the fusion-negative and fusion-positive tumors.

ii) MIB-1 expression $>10 \%$ we found predominately $(87.5 \%)$ in high grade tumors (G3), whereas the most $(89 \%)$ of the low to intermediate tumors (G1 to G2) were associated with MIB-1 expression $<10 \%$. Published immunohistochemical studies demonstrated also that high Ki-67 expression is significantly correlated with higher grade tumors $(11,34,35)$. Regarding the fusion status we found more frequent MIB-1 expression $<10 \%$ in fusion transcriptpositive tumors than in MECT1-MAML2-negative tumors (77.8 vs. $22.2 \%$ ). The part of our samples with expression greater than $10 \%$ was slightly lower in fusion-positive tumors (44.4 vs. 55.6\%). In addition to our findings, the status of Ki-67-expression supplies additional prognostic information regarding tumor behavior.

iii) Extensive and systematic molecular genetic data for malignant tumors of the salivary gland have not been previously reported. Previous cytogenetic studies (by Gbanding, SKY, FISH) of MECs of the salivary gland reported other, besides the common $\mathrm{t}(11 ; 19)$, aberrations like $-\mathrm{Y},+5$, $+7,+8,-14,+\mathrm{X}$ and translocations involving chromosome 1 , $3,5,6,8,12,13,15,16$ and $20(11,15,21,25-30)$. To our knowledge, only two MEC cell lines with CGH data are available in the literature (21). In the first cell line gains or amplifications on 1q31, 5p, 6p22, 7pter-p15, 8q21.3-qter, 11p13-qter, 15q25-qter and losses of chromosome 9 and 20 were found. Frequent aberrations in the second analyzed cell line were gains at 3pter-p24, 3q, 7pter-q11.2 and 20. The regions 3p21-p13, 4p16, 4q32-qter, 5q32-qter and 8pter-p12 were under-represented.

The most frequent findings in our tumors were gains of $\mathrm{X}$ in 5 cases, partial or complete losses on chromosome 1 , 2 and 15 in 4 cases, followed by gain of $7 / 7 \mathrm{p}, 19 / 19 \mathrm{p}$ and 20/20p/20q. MECs are characterized by a $\mathrm{t}(11 ; 19)(\mathrm{q} 21 ; \mathrm{p} 13)$ translocation, more often occurring as sole anomaly being a simple translocation or complex one $(6,31)$. The findings are only in partial concordance with the data by Tonon et al (21) and Behboudi et al (23) regarding gain on chromosome 7, 20, $\mathrm{X}$ and loss of $8 \mathrm{p}$ and 15.

iv) Copy number variation (CNV) and presence of MCET1MAML2 fusion transcript: patients with fusion gene-positive tumors showed higher CNV (5.25 vs. 4.0) in fusion-negative tumors; whereas MECT1-MAML2-positive tumors showed more losses than gains/case (3.25 vs. 2.0) the number of losses and gains/case was approximately equal (1.8 losses vs. 2.2 gains) in fusion transcript negative tumors. In $62.5 \%$ of the fusion-positive tumors we detected more than $2 \mathrm{CNV}$ in comparison with $80 \%$ in the fusion-negative tumors. Regarding the CGH-aberration spectrum, losses of $6 \mathrm{p}, 8 \mathrm{p}, 22$ and gain of chromosome 7 and 18 were found only in MECT1-MAML2positive tumors.

We concluded that the presence of MECT1-MAM12 fusion transcript in MECs may define, in view to clinical and pathological outcome, a subset of tumors with more favorable outcome. Our findings in MECT1-MAML2transcipt-positive tumors as a subgroup of MECs with regard to a better clinicopathological outcome is in agreement with most other publications. It remains to be clarified, if the presence of this aberration represents a useful diagnostic marker for prognosis and prediction of the biological tumor behavior.

\section{Acknowledgements}

The study of salivary gland tumors is supported by the Austrian Cancer Society/Tirol, the 'Fonds zur Förderung von Wissenschaft und Forschung an den Universitätskliniken Innsbruck' and the 'Medizinischer Forschungsfonds Tirol'.

\section{References}

1. Ellis GL and Auclair PL: Atlas of Tumor Pathology. Tumors of the Salivary Glands. Armed Forces Institute of Pathology, AFIP, Washington, 1996.

2. Martins C, Fonseca I, Roque L, Pinto AE and Soares J: Malignant salivary gland neoplasms: a cytogenetic study of 19 cases. Eur J Cancer B Oral Oncol 32B: 128-132, 1996.

3. Toida M. Balázs M, Mori T, Ishimaru JI, Ichihara H, Fujitsuka H, Hyodo I, Yokoyama K, Tatematsu N and Adány R: Analysis of genetic alterations in salivary gland tumors by comparative genomic hybridization. Cancer Genet Cytogenet 127: 34-37, 2001.

4. Cerilli LA, Swartzbaugh JR, Saadut R, Marshall CE, Rumpel CA, Moskaluk CA and Frierson HF: Analysis of chromosome 9p21 deletion and p16 gene mutation in salivary gland carcinomas. Hum Pathol 30: 1242-1246, 1999.

5. Nordkvist A, Gustafsson H, Juberg-Ode M and Stenman G: Recurrent rearrangement of 11q14-22 in mucoepidermoid carcinoma. Cancer Genet Cytogenet 74: 77-83, 1994.

6. Mitelman Database of Chromosome Aberrations in Cancer. In: Mitelman F. Johansson B and Mertens F (eds.) Available at: http://cgap.nci.gov/Chromosomes/Mitelman, 2005.

7. Wu L, Liu J, Gao P, Nakamura M, Cao Y, Shen $H$ and Griffin JD: Transforming activity of MECT1-MAML2 fusion oncoprotein is mediated by constitutive CREB activation. EMBO J 24: 2391-2402, 2005.

8. Bell D, Luna MA, Weber RS, Kaye FJ and El-Naggar AK: CRTC1-MAML2 fusion transcript in Warthin's tumor and mucoepidermoid carcinoma: evidence for a common genetic association. Genes Chromosomes Cancer 47: 309-314, 2008.

9. Fehr A, Röser K, Belge G, Löning T and Bullerdiek J: A closer look at Warthin tumors and the $\mathrm{t}(11 ; 19)$. Cancer Genet Cytogenet 180: 135-139, 2008.

10. Bullerdiek J, Haubrich J, Meyer K and Bartnitzke S: Translocation $\mathrm{t}(11 ; 19)(\mathrm{q} 21 ; \mathrm{p} 13.1)$ as the sole chromosome abnormality in a cystadenolymphoma (Warthin's tumor) of the parotid gland. Cancer Genet Cytogenet 35: 129-135, 1988.

11. Behboudi A, Enlund F, Winnes M, Andrén Y, Nordkvist A, Leivo I, Flaberg E, Szekely L, Mäkitie A, Grenman R, Mark J and Stenman G: Molecular classification of mucoepidermoid carcinomas - prognostic significance of the MECT1-MAML2 fusion oncogene. Genes Chromosomes Cancer 45: 470-481, 2006. 
12. Dahlenfors R, Wedell B, Rundrantz $\mathrm{H}$ and Mark J: Translocation $(11 ; 19)(\mathrm{q} 14-21 ; \mathrm{p} 12)$ in a parotid mucoepidermoid carcinoma of a child. Cancer Genet Cytogenet 79: 188, 1995.

13. Stenman G, Sandros J, Dahlenfors R, Juberg-Ode M and Mark J: 6q- and loss of the Y chromosome - two common deviation in malignant human salivary gland tumors. Cancer Genet Cytogenet 22: 283-293, 1986.

14. Sandros J, Mark J, Happonen RP and Stenman G: Specificity of 6q- markers and other recurrent deviations in human malignant salivary gland tumors. Anticancer Res 8: 637-643, 1988.

15. Jin Y, Mertens F, Limon J, Mandahl N, Wennerberg J, Dictor M, Heim S and Mitelman F: Characteristic karyotypic features in lacrimal and salivary gland carcinomas. $\mathrm{Br} \mathrm{J}$ Cancer 70: 42-47, 1994

16. Fehr A, Röser K, Heidorn K, Hallas C, Löning T and Bullerdiek J: A new type of MAML2 fusion in mucoepidermoid carcinoma. Genes Chromosomes Cancer 47: 203-206, 2008

17. Tonon G, Modi S, Wu L, Kubo A, Coxon AB, Komiya T, O'Neil K, Stover K, El-Naggar A, Griffin JD, Kirsch IR and Kaye FJ: t(11;19)(q21;p13) translocation in mucoepidermoid carcinoma creates a novel fusion product that disrupts a NOTCH signaling pathway. Nat Genet 33: 208-213, 2003

18. Enlund F, Behboudi A, Andrén Y, Oberg C, Lendahl U, Mark J and Stenman G: Altered Notch signaling resulting from expression of a WAMTP1-MAML2 gene fusion in mucoepidermoid carcinomas and benign Warthin's tumors. Exp Cell Res 292: 21-28, 2004.

19. Martins C, Cavaco B, Tonon G, Kaye FJ, Soares J and Fonseca I: A study of MECT1-MAML2 in mucoepidermoid carcinoma and Warthin's tumor of salivary glands. J Mol Diagn 6: 205-210, 2004.

20. Serra A, Schackert HK, Mohr B, Weise A, Liehr T and Fitze G: $\mathrm{t}(11 ; 19)(\mathrm{q} 21 ; \mathrm{p} 12 \sim \mathrm{p} 13.11)$ and MECT1-MAML2 fusion transcript expression as a prognostic marker in infantile lung mucoepidermoid carcinoma. J Pediatr Surg 42: E23-E29, 2007.

21. Tonon G, Gelhaus KS, Yonescu R, Kaye FJ and Kirsch IR: Multiple reciprocal translocations in salivary gland mucoepidermoid carcinomas. Cancer Genet Cytogenet 152: 15-22, 2004.

22. Winnes M, Mölne L, Suurküla M, Andrén Y, Persson F, Enlund F and Stenman G: Frequent fusion of the CRTC1 and MAML2 genes in clear cell variants of cutaneous hidradenomas. Genes Chromosomes Cancer 46: 559-563, 2007.

23. Behboudi A, Winnes M, Gorunova L, van den Oord JJ, Mertens F, Enlund F and Stenman G: Clear cell hidradenoma of the skin-a third tumor type with a $t(11 ; 19)$-associated TORC1-MAML2 gene fusion. Genes Chromosomes Cancer 43: 202-205, 2005.

24. Goode RK and El-Naggar AK: Mucoepidermoid carcinoma. In: Pathology \& Genetics. Head and Neck Tumours. Barnes L, Eveson JW, Reichart P and Sidransky D (eds). IARC Press, Lyon, pp219-220, 2005
25. Bullerdiek J, Vollrath M, Wittekind C, Caselitz J and Bartnitzke S: Mucoepidermoid tumor of the parotid gland showing a translocation $(3 ; 8)(\mathrm{p} 21 ; \mathrm{q} 12)$ and a deletion $(5)(\mathrm{q} 22)$ as sole chromosome abnormalities. Cancer Genet Cytogenet 50: 161164,1990

26. El-Naggar AK, Lovell M, Killary A and Batsakis JG: Trisomy 5 as the sole chromosomal abnormality in a primary mucoepidermoid carcinoma of the minor salivary gland. Cancer Genet Cytogenet 76: 96-99, 1994.

27. El-Naggar AK, Lovell M, Killary AM and Batsakis JG: Genotypic characterization of a primary mucoepidermoid carcinoma of the parotid gland by cytogenetic, fluorescence in situ hybridization, and DNA ploidy analysis. Cancer Genet Cytogenet 89: 38-43, 1996.

28. Horsman DE, Berean K and Durham JS: Translocation $(11 ; 19)(q 21 ; p 13.1)$ in mucoepidermoid carcinoma of salivary gland. Cancer Genet Cytogenet 80: 165-166, 1995.

29. Hrynchak M, White V, Berean K and Horsman D: Cytogenetic findings in seven lacrimal gland neoplasms. Cancer Genet Cytogenet 75: 133-138, 1994.

30. Jin C, Martins C, Jin Y, Wiegant J, Wennerberg J, Dictor M, Gisselsson D, Strömbeck B, Fonseca I, Mitelman F, Tanke HJ, Höglund $\mathrm{M}$ and Mertens $\mathrm{F}$ : Characterization of chromosome aberrations in salivary gland tumors by FISH, including multicolor COBRA-FISH. Genes Chromosomes Cancer 30: 161-167, 2001.

31. El-Naggar AK, Lovell M, Killary AM, Clayman GL and Batsakis JG: A mucoepidermoid carcinoma of minor salivary gland with $\mathrm{t}(11 ; 19)(\mathrm{q} 21 ; \mathrm{p} 13.1)$ as the only karyotypic abnormality. Cancer Genet Cytogenet 87: 29-33, 1996.

32. Okabe M, Miyabe S, Nagatsuka H, Terada A, Hanai N, Yokoi M, Shimozato K, Eimoto T, Nakamura S, Nagai N, Hasegawa Y and Inagaki H: MECT1-MAML2 fusion transcript defines a favorable subset of mucoepidermoid carcinoma. Clin Cancer Res 12: 3902-3907, 2006.

33. Tirado Y, Williams MD, Hanna EY, Kaye FJ, Batsakis JG and El-Naggar AK: CRTC1/MAML2 fusion transcript in high grade mucoepidermoid carcinomas of salivary and thyroid glands and Warthin's tumours: implications for histogenesis and biologic behaviour. Genes Chromosomes Cancer 46: 708-715, 2007.

34. Triantafillidou K, Dimitrakopoulos J, Iordanidis F and Koufogiannis D: Mucoepidermoid carcinoma of minor salivary glands: a clinical study of 16 cases and review of the literature. Oral Dis 12: 364-370, 2006.

35. Goode RK, Auclair PL and Ellis GL: Mucoepidermoid carcinoma of the major salivary glands: clinical and histopathologic analysis of 234 cases with evaluation of grading criteria. Cancer 82: 1217-1224, 1998. 